\title{
Studying the Impact of Contextual Data on the Outcomes of the Individual Educational Achievements of the Fourth-grade Pupils While Assessing the Metasubject Results Obtained at the General Education Institutions of Voronezh Region
}

\author{
Ruslan Chudinsky \\ Educational Development Institute \\ Voronezh, Russia \\ E-mail: chudinsky@mail.ru
}

\author{
Alexander Volodin \\ Russian State Specialized Academy of Arts \\ Moscow, Russia \\ E-mail: voalan@list.ru
}

\author{
Anatoliy Bykanov \\ Educational Development Institute \\ Voronezh, Russia \\ E-mail: asbikanov@mail.ru
}

\begin{abstract}
The article contains an account on the empirical study regarding the impact of contextual data on the outcomes of the individual educational achievements of the fourth-grade pupils while assessing the metasubject results obtained at the general education institutions of Voronezh region. The phases, the details, the conditions and the procedure for the empirical study are specified and described. To assess the impact of contextual data on the outcomes of the individual educational achievements of the fourth-grade pupils, the statistical methods were used in the course of the empirical study i.e. correlationand-regression analysis and one-way analysis of variance (OneWay ANOVA). The specified methods, taken together, allow for identification of internal relationships and regularities of dependence of the outcomes of the individual educational achievements of the fourth-grade pupils while assessing the metasubject results on the contextual data provided by the educational institutions.
\end{abstract}

Keywords-study; education; individual educational achievements; metasubject results; assessment; pupils

\section{INTRODUCTION}

Currently, as part of implementation of the Unified system of school education quality assessment in the Russian Federation, the assessment of education outcomes of the pupils is provided for. Such assessment is being carried out consistently at the federal, regional and municipal levels, at the level of an educational institution and, eventually, at the individual level of each pupil. In this regard, the modern approaches to assessment of the education outcomes at the general education level involve the analysis of impact of contextual data on the level of the educational achievements of the pupils.

The idea of using the contextual data while assessing the quality of education has been developed in the studies of the domestic and the foreign scholars. As noted by G.A. Yastrebov, M.A. Pinskaya, S.G. Kosaretsky, “...in the broadest sense of the term, by context we mean the surroundings or the system of circumstances, in which any given process or phenomenon acquires a particular meaning. ...W With regard to the education system, the context can be defined as the circumstances, in which the educational process is running, but the circumstances which are external in relation to this process, i.e. which are not the direct part of it, yet they exert a considerable impact on it. Essentially, this refers to the set of external facts, which are not always obvious, and which cannot be controlled by the participants of the educational process, but which cannot be ignored when assessing the outcomes of this process" [1].

It must be noted that, in the domestic and foreign educational practices, the analysis of impact of contextual data on the level of the educational achievements of pupils is being performed within the framework of the international comparative researches: PIRLS, PISA, TIMSS and others. As noted by K.N. Polivanova, "today, these international researches are the most comprehensive and rigorous international programs for assessment of the learning and general-educational achievements, and also with regard to the width and the outreach to the additional (contextual) information about the pupils themselves, their families, the institutional factors, the characteristics of the education system (through the questionnaires filled out by the pupils, 
the teachers, the administrators, the heads of the education system, and in some cases - by the parents). Together, these data make it possible to highlight the most important factors and trends in education on the international scale. It is only the combination of the contextual information with the test results that allows obtaining quite a wide range of information which is not only indicative, but also analytical in nature."[2] In its turn, the analysis of impact of the contextual data on the level of the educational achievements of pupils is also being conducted in the course of the domestic researches concerning the quality of education: the National Research on the Quality of Education (NIKO) and All-Russian Control Works (VPR).

At the same time, the domestic researches do not include the analysis of impact of the contextual data on the outcomes of the individual educational achievements of the fourthgrade pupils while assessing the metasubject results, the existing studies do not contain the assessment of causeeffect links, statistical or other relationships in the area of research. Consequently, there is a contradiction between the need for analysis of impact of the contextual data on the outcomes of the individual educational achievements of the fourth-grade pupils while assessing the metasubject results and the absence of such assessment.

To settle the identified contradiction, in the present paper, the authors have set the following goal - to perform the assessment of impact of the contextual data on the outcomes of the individual educational achievements of the fourthgrade pupils while assessing the metasubject results of the general education institutions in the Voronezh region.

According to the hypothesis suggested and tested by the authors in the study, if the regularities characterizing the impact of the contextual data on the outcomes of the individual educational achievements of the fourth-grade pupils while assessing the metasubject results are identified, then it will allow for determination of the factors influencing the outcomes of the individual educational achievements of the fourth-grade pupils while assessing the metasubject results during the implementation of the Federal State Educational Standard (FSES) for the primary general education.

\section{METHODOLOGY OF THE EMPIRICAL STUDY}

To perform the assessment of the impact of the contextual data of the educational institutions on the results of monitoring of the individual educational achievements of the fourth-grade pupils in terms of assessment of metasubject results during the implementation of FSES for the primary general education, the statistical methods have been used the correlation-and-regression analysis and the one-way analysis of variance $[3 ; 4]$. These methods, taken together, allow for identification of internal relationships and regularities of the impact of the contextual data provided by the general education institutions on the results of monitoring of the individual educational achievements of the fourthgrade pupils in terms of assessment of metasubject results during the implementation of FSES for the primary general education.
Correlation is viewed as an indicator of the interrelationship of a number of numerical sequences, i.e. it characterizes the interrelationship that is present in the data. When searching for correlation dependence, the probabilistic connection between one variable $\mathrm{x}$ and other variable - $\mathrm{y}$ is identified. Thus, the correlation analysis allows for making a conclusion on the strength of relationship between data pairs $\mathrm{x}$ and $\mathrm{y}$. More precise estimation of the correlation ratio between the quantitative indicators can be obtained when determining the measure of correspondence of the variation of the effective feature and the variation of the factorial feature. For measuring the correlation ratio between the effective feature $\mathrm{y}$ and the factorial feature $\mathrm{x}$, we shall apply the linear correlation coefficient.

Regression analysis allows for estimating the analytical dependence, which shows how the mean value of the effective feature changes under the influence of one or several independent variables. Besides, many other factors, also influencing the effective feature, are taken for constant or mean levels. Thus, the regression analysis is indicative of how one variable, for example $y$, changes on the average, given the corresponding changes of another variable $\mathrm{x}$, and, vice versa, to what extent the variable $x$ changes per unit of changing of the variable $y$.

Applying the correlation-and-regression analysis will allow us, on the one hand, to reveal the character of statistical interrelationship of the obtained experimental variables, and, on the other hand, to reveal the mathematical expressions characterizing the regularities of the relationships between these experimental variables. As the experimental variables $-\mathrm{k}$, which are under consideration in the present study, are taken the results of the monitoring of the individual educational achievements of the fourth-grade pupils in terms of assessing the metasubject results during the implementation of FSES for the primary general education.

One-way analysis of variance (ANOVA) is used for comparison of the mean values for three or more samples. The essence of the analysis of variance is to study the impact of one or several independent variables, generally known as factors, on the dependent variable. The independent variable which influences the dependent variable is called a factor. As a dependent variable in the present study are taken the results of the monitoring of the individual educational achievements of the fourth-grade pupils in terms of assessing the metasubject results during the implementation of FSES for the primary general education, and as a factor (an independent variable) are taken the contextual data provided by the educational institutions.

The procedure of monitoring the individual educational achievements of the fourth-grade pupils in terms of assessing the metasubject results during the implementation of FSES for the primary general education involved 10,482 fourthgrade pupils from 226 educational institutions of Voronezh region. The results of the monitoring of the individual educational achievements of the fourth-grade pupils in terms of assessing the metasubject results during the 
implementation of FSES for the primary general education are presented in the corresponding report [5].

To perform the analysis of the results of the monitoring of the individual educational achievements of the fourthgrade pupils in terms of assessing the metasubject results during the implementation of FSES for the primary general education, the following contextual data were requested from the participating educational institutions:

- The percentage of the fourth-grade pupils raised in single-parent families compared to the total number of the fourth-grade pupils;

- The percentage of the fourth-grade pupils raised in the families where both parents have higher education;

- The percentage of the fourth-grade pupils raised in the families where at least one parent has higher education;

- The percentage of the primary school teachers having the highest qualification grade;

- The percentage of the primary school teachers younger than of 35 years old;

- The percentage of teachers older than 60 years old;

- The percentage of teachers who teach the school subjects corresponding to the first Teacher Education diploma;
- The average salary for a teacher at the educational institution;

- The speed of incoming Internet traffic (Mbps) at the educational institution.

\section{PRESENTATION OF RESUlts}

Let us perform calculations in accordance with the following three phases:

- Construction of correlation matrix and estimation of the character of the relationship between the variables.

- Construction of regression and determination of mathematical expressions characterizing the regularities of the relationship between the variables.

- Conduction of one-way analysis of variance and estimation of impact of the contextual data provided by the educational institutions on the results of the monitoring of the individual educational achievements of the fourth-grade pupils in terms of assessing the metasubject results during the implementation of FSES for the primary general education.

During the first phase, for construction of a correlation matrix we have used Microsoft Excel software solution. Based on the data aggregation, the following correlation values have been obtained in "Table I".

TABLE I. CORRELATION MATRIX OF INTERRELATIONSHIP BETWEEN THE CONTEXTUAL DATA PROVIDED BY THE EDUCATIONAL INSTITUTIONS AND THE RESUlTS OF MONITORING OF THE INDIVIDUAL EDUCATIONAL ACHIEVEMENTS OF THE FOURTH-GRADE PUPILS IN TERMS OF ASSESSING THE METASUBJECT RESULTS DURING THE IMPLEMENTATION OF FSES FOR THE PRIMARY GENERAL EDUCATION

\begin{tabular}{|l|l|}
\multicolumn{1}{|c|}{ Title of the independent factor } & \multicolumn{1}{|c|}{$\begin{array}{c}\text { Values of coefficients of the correlation } \\
\text { between independent and dependent factors }\end{array}$} \\
\hline percentage of the fourth-grade pupils raised in single-parent families & $-0,014$ \\
\hline $\begin{array}{l}\text { percentage of the fourth-grade pupils raised in the families where both parents have } \\
\text { higher education }\end{array}$ & 0,52 \\
\hline $\begin{array}{l}\text { percentage of the fourth-grade pupils raised in the families where at least one parent } \\
\text { has higher education }\end{array}$ & 0,428 \\
\hline percentage of the primary school teachers having the highest qualification grade & 0,409 \\
\hline percentage of the primary school teachers younger than of 35 years old & 0,073 \\
\hline percentage of teachers older than 60 years old & $-0,109$ \\
\hline $\begin{array}{l}\text { percentage of teachers who teach the school subjects corresponding to the first } \\
\text { Teacher Education diploma }\end{array}$ & 0,072 \\
\hline percentage of the average salary for teachers for Voronezh region & 0,19 \\
\hline speed of incoming Internet traffic (Mbps) at the educational institution & 0,337 \\
\hline
\end{tabular}

The performed analysis of value of coefficients of correlation has shown that, generally, the contextual data provided by the educational institutions and the results of monitoring of the individual educational achievements of the fourth-grade pupils in terms of assessing the metasubject results during the implementation of FSES for the primary general education are not closely-interrelated. At the same time, of particular interest for the study is the closest correlative relationship which has been identified between the results of the monitoring of the individual educational achievements of the fourth-grade pupils in terms of assessing the metasubject results during the implementation of FSES for the primary general education and the contextual data.
Consequently, based on the calculations presented in the correlation matrix (see "Table I") and with account for the Cheddok scale [6] for estimation of the correlation, the following conclusions may be drawn:

- Subject to interpretation shall be the relationship between the results of the monitoring of the individual educational achievements of the fourthgrade pupils in terms of assessing the metasubject results during the implementation of FSES for the primary general education and the percentage of the fourth-grade pupils raised in families where both parents have higher education, both direct and obvious one; 
- Subject to interpretation shall be the relationship between the results of the monitoring of the individual educational achievements of the fourthgrade pupils in terms of assessing the metasubject results during the implementation of FSES for the primary general education and the percentage of the fourth-grade pupils raised in families where at least one parent has higher education, both direct and moderate one;

- Subject to interpretation shall be the relationship between the results of the monitoring of the individual educational achievements of the fourthgrade pupils in terms of assessing the metasubject results during the implementation of FSES for the primary general education and the percentage of the primary school teachers having the highest qualification grade, both direct and moderate one;

- Subject to interpretation shall be the relationship between the results of the monitoring of the individual educational achievements of the fourthgrade pupils in terms of assessing the metasubject results during the implementation of FSES for the primary general education and the speed of incoming Internet traffic (Mbps) at the educational institution, both direct and moderate one.

According to the second phase, let us construct regressions and determine the mathematical expressions characterizing the regularities of the relationship between the variables.

First comes the regression depicting the approximating function (the approximee) of correlation of the results of the monitoring of the individual educational achievements of the fourth-grade pupils in terms of assessing the metasubject results during the implementation of FSES for the primary general education and the percentage of the fourth-grade pupils raised in families where both parents have higher education (see "Fig. 1").

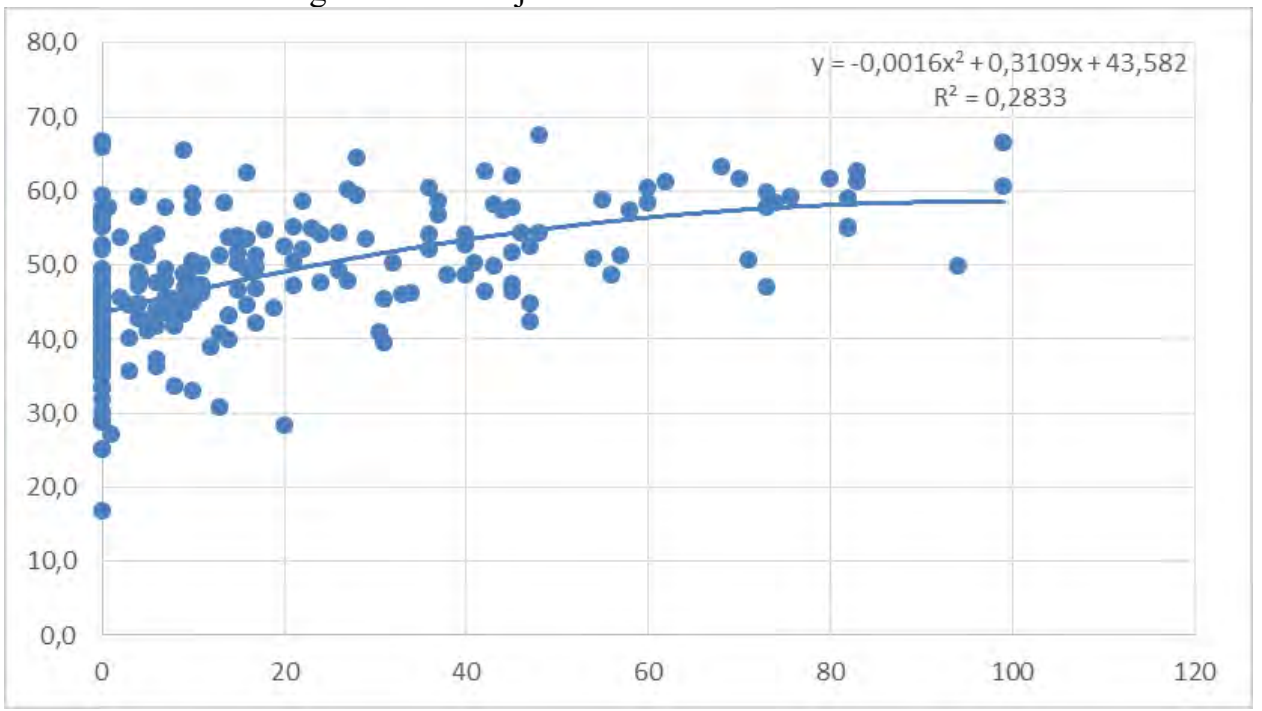

Fig. 1. Regression of correlation of the outcomes of the individual educational achievements of the fourth-grade pupils at the general education institutions of Voronezh region in terms of assessing the metasubject results during the implementation of FSES for the primary general education and the percentage of the fourth-grade pupils raised in families where both parents have higher education.

From "Fig. 1" we can see the line of regression depicting the character of interrelationship of the outcomes of the individual educational achievements of the fourth-grade pupils at the general education institutions of Voronezh region in terms of assessing the metasubject results during the implementation of FSES for the primary general education and the percentage of the fourth-grade pupils raised in families where both parents have higher education. Besides, the function (the equation) approximating the line of regression is determined (1):

$$
y=-0,0016 x 2+0,3109 x+43,582
$$

The calculated function is a polynominal one and is characterized by the approximation reliability value $\mathrm{R} 2=$ 0,2883 . The obtained function allows for calculating the twoway relationship values i.e. how the outcomes of the individual educational achievements of the fourth-grade pupils at the general education institutions in Voronezh region in terms of assessing the metasubject results during the implementation of FSES for the primary general education change on the average, given the corresponding changes of percentage of the fourth-grade pupils raised in the families where both parents have higher education.

Let us calculate the regression approximating the function of correlation of the results of the monitoring of the individual educational achievements of the fourth-grade pupils at the general education institutions in Voronezh region in terms of assessing the metasubject results during the implementation of FSES for the primary general education and the percentage of the fourth-grade pupils 
raised in families where at least one parent has higher education (see "Fig. 2").

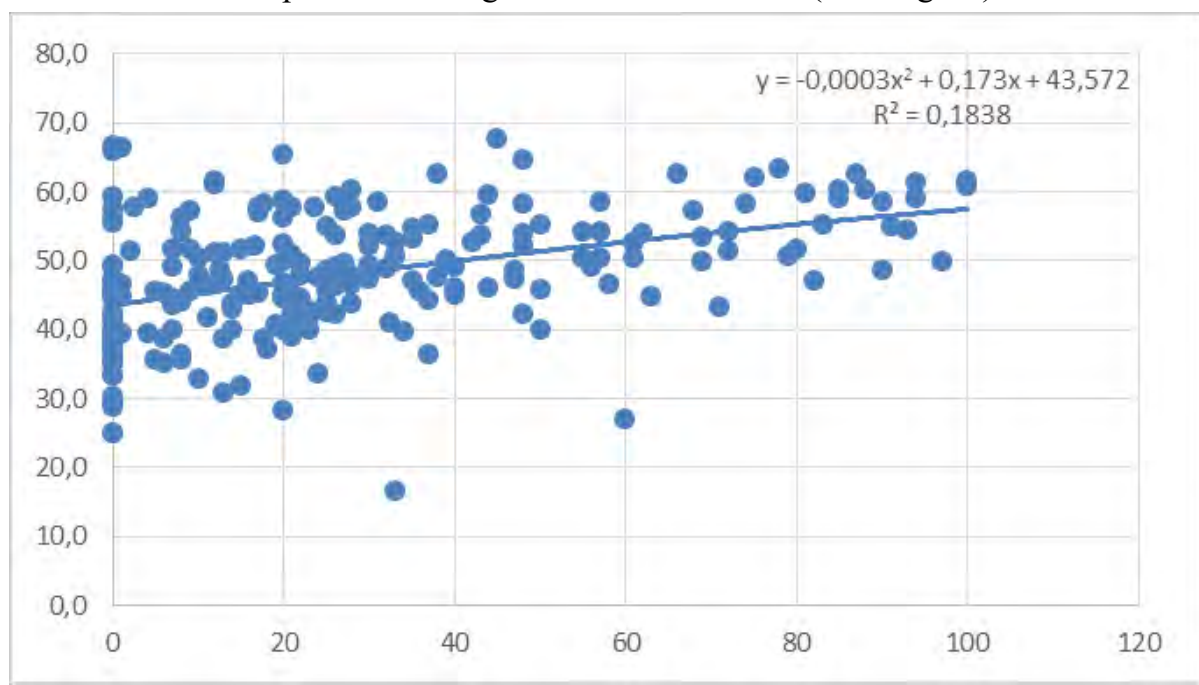

Fig. 2. Regression of correlation of the outcomes of the individual educational achievements of the fourth-grade pupils at the general education institutions of Voronezh region in terms of assessing the metasubject results during the implementation of FSES for the primary general education and the percentage of the fourth-grade pupils raised in families where at least one parent has higher education.

From "Fig. 2" we can see the line of regression depicting the character of interrelationship of the outcomes of the individual educational achievements of the fourth-grade pupils at the general education institutions of Voronezh region in terms of assessing the metasubject results during the implementation of FSES for the primary general education and the percentage of the fourth-grade pupils raised in families where at least one parent has higher education. Besides, the function (the equation) approximating the line of regression is determined (2):

$$
y=-0,0003 x^{2}+0,173 x+43,572
$$

The calculated function is a polynominal one and is characterized by the approximation reliability value $\mathrm{R}^{2}=$ 0,1838 . The obtained function allows for calculating the two- way relationship values i.e. how the outcomes of the individual educational achievements of the fourth-grade pupils at the general education institutions in Voronezh region in terms of assessing the metasubject results during the implementation of FSES for the primary general education change on the average, given the corresponding changes of percentage of the fourth-grade pupils raised in the families where at least one parent has higher education.

Let us calculate the third regression approximating the function of correlation between the results of the monitoring of the individual educational achievements of the fourthgrade pupils in terms of assessing the metasubject results during the implementation of FSES for the primary general education and the percentage of the primary school teachers having the highest qualification grade (see "Fig. 3").

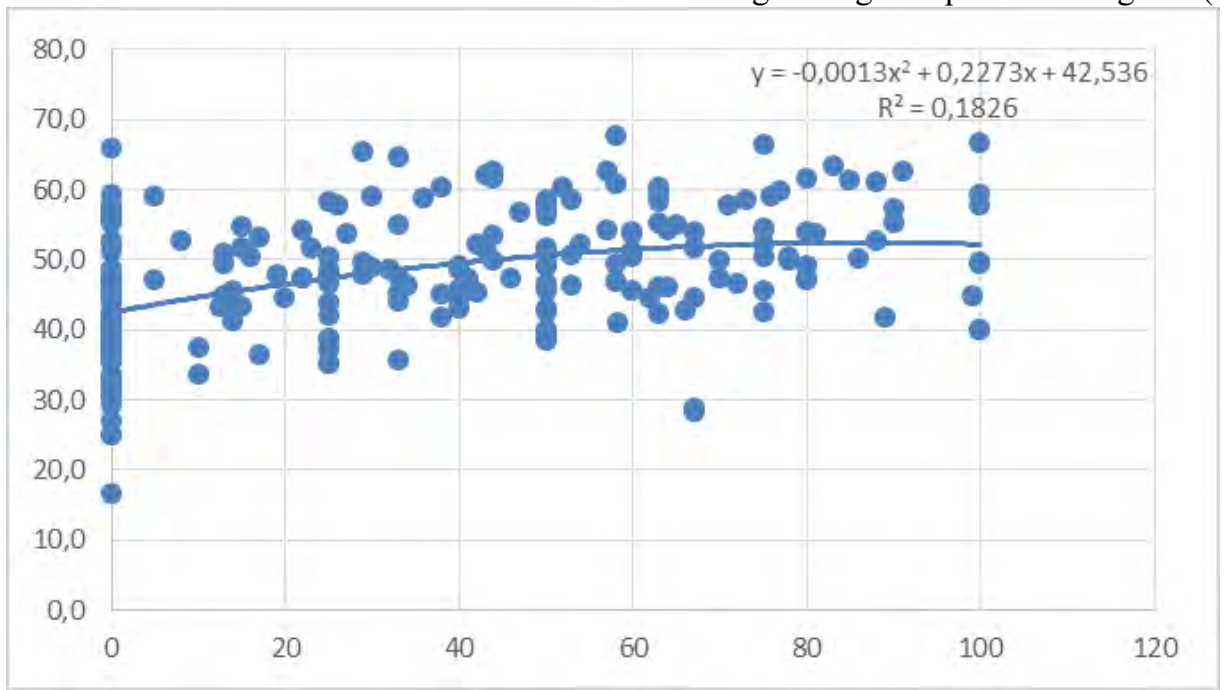

Fig. 3. Regression of correlation of the outcomes of the individual educational achievements of the fourth-grade pupils at the general education institutions of Voronezh region in terms of assessing the metasubject results during the implementation of FSES for the primary general education and the percentage of the primary school teachers having the highest qualification grade. 
From "Fig. 3" we can see the line of regression depicting the character of interrelationship of the outcomes of the individual educational achievements of the fourth-grade pupils at the general education institutions of Voronezh region in terms of assessing the metasubject results during the implementation of FSES for the primary general education and the percentage of the primary school teachers having the highest qualification grade. Besides, the function (the equation) approximating the line of regression is determined (3):

$$
y=-0,0013 x^{2}+0,2273 x+43,536
$$

The calculated function is a polynominal one and is characterized by the approximation reliability value $\mathrm{R}^{2}=$ 0,1826 . The obtained function allows for calculating the two- way relationship values i.e. how the outcomes of the individual educational achievements of the fourth-grade pupils at the general education institutions in Voronezh region in terms of assessing the metasubject results during the implementation of FSES for the primary general education change on the average, given the corresponding changes of percentage of the primary school teachers having the highest qualification grade.

Let us calculate the fourth regression approximating the function of correlation between the results of the monitoring of the individual educational achievements of the fourthgrade pupils in terms of assessing the metasubject results during the implementation of FSES for the primary general education and the speed of incoming Internet traffic (Mbps) at an educational institution (see "Fig. 4").

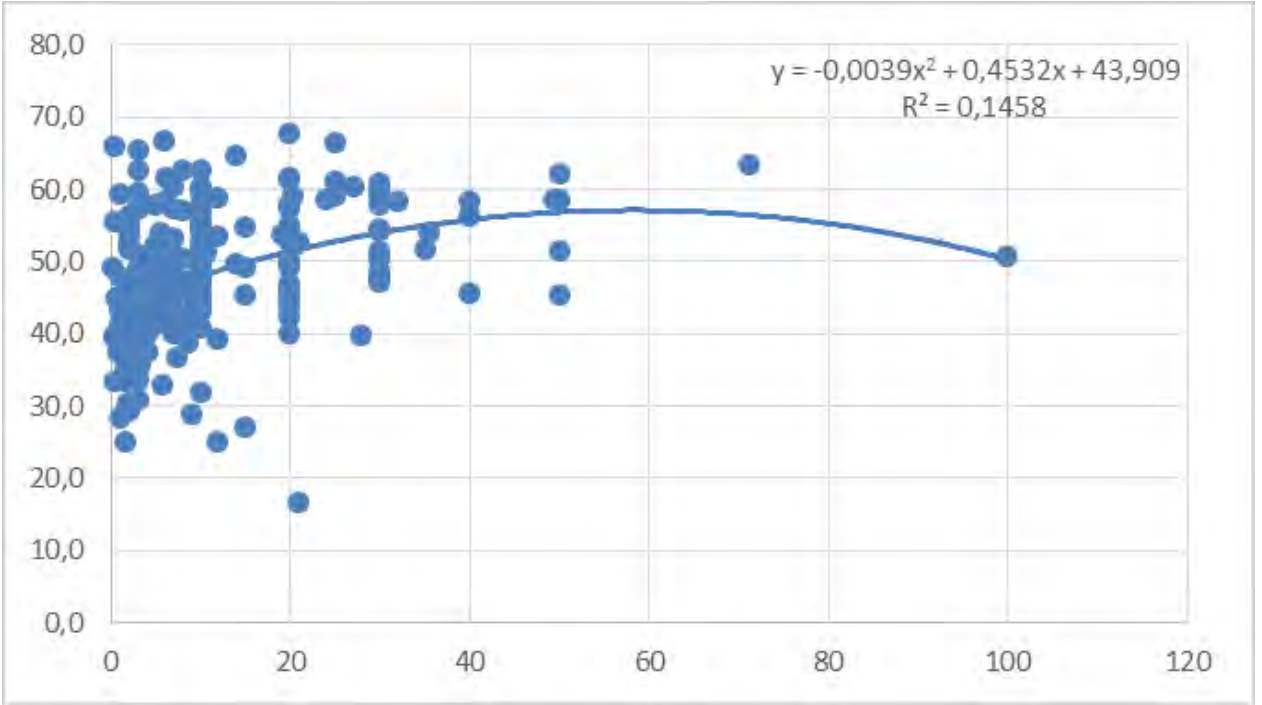

Fig. 4. Regression of correlation of the outcomes of the individual educational achievements of the fourth-grade pupils at the general education institutions of Voronezh region in terms of assessing the metasubject results during the implementation of FSES for the primary general education and the speed of incoming Internet traffic (Mbps) at the educational institution.

From "Fig. 4" we can see the line of regression depicting the character of interrelationship of the outcomes of the individual educational achievements of the fourth-grade pupils at the general education institutions of Voronezh region in terms of assessing the metasubject results during the implementation of FSES for the primary general education and the percentage of speed of the incoming Internet traffic (Mbps) at an educational institution. Besides, the function (the equation) approximating the line of regression is determined (4):

$$
y=-0,0039 x^{2}+0,4532 x+43,909
$$

The calculated function is a polynominal one and is characterized by the approximation reliability value $\mathrm{R}^{2}=$ 0,1458 . The obtained function allows for calculating the twoway relationship values i.e. how the outcomes of the individual educational achievements of the fourth-grade pupils at the general education institutions in Voronezh region in terms of assessing the metasubject results during the implementation of FSES for the primary general education change on the average, given the corresponding changes of speed of incoming Internet traffic (Mbps) at an educational institution.

According to the third phase of the study, let us perform the one-way analysis of variance (ANOVA) and estimate the impact of all collected contextual data provided by the general education institutions on the outcomes of the individual educational achievements of the fourth-grade pupils at the general education institutions of Voronezh region in terms of assessing the metasubject results during the implementation of FSES for the primary general education. Let us find out, if there are any differences in the impact of all collected contextual data provided by the general education institutions on the outcomes of the individual educational achievements of the fourth-grade pupils at the general education institutions on the whole for the general education institutions in Voronezh region.

In total, there are 226 general education institutions in Voronezh region participating in the monitoring of the individual educational achievements of the fourth-grade pupils in terms of assessing the metasubject results during 
the implementation of FSES for the primary general education.

Let us suggest a null-hypothesis, according to which all mean values taken from various aggregations of $k$ (contextual data) are equal among one another.

$$
\mathrm{H}_{0}: \mu_{1}=\mu_{\mathrm{k}} \text { (all equal), (or } X_{1}=X_{2}=\ldots=X_{k} \text { ). }
$$

An alternative hypothesis states that at least any two mean values are not equal among one another.
$\mathrm{H}_{1}: \mu_{1} \neq \mu_{\mathrm{k}}$ (at least two are not equal), (or $X_{l} \neq X_{k}$ ).

The results arising from calculation of one-way analysis of variance (ANOVA) of the impact of all collected contextual data provided by the general education institutions on the outcomes of the individual educational achievements of the fourth-grade pupils at the general education institutions of Voronezh region participating in the assessment of the metasubject results during the implementation of FSES for the primary general education are presented in "Table II".

TABLE II. RESUlts ARISING From CALCUlAtion OF ONE-WAY ANALYSIS OF VARIANCE (ANOVA) OF THE IMPACT OF THE CONTEXTUAL DATA PROVIDED BY THE GENERAL EDUCATION INSTITUTIONS ON THE OUTCOMES OF THE INDIVIDUAL EDUCATIONAL ACHIEVEMENTS OF THE FOURTH-GRADE PUPILS AT THE GENERAL EDUCATION INSTITUTIONS OF VORONEZH REGION PARTICIPATING IN THE ASSESSMENT OF THE METASUBJECT RESULTS DURING THE IMPLEMENTATION OF FSES FOR THE PRIMARY GENERAL EDUCATION

\begin{tabular}{|c|c|c|c|c|c|c|c|}
\hline \multicolumn{8}{|l|}{ Final Results } \\
\hline Groups & \multicolumn{2}{|c|}{ Count } & Total amount & \multicolumn{2}{|c|}{ Mean value } & \multicolumn{2}{|c|}{ Variance } \\
\hline Column 1 & \multicolumn{2}{|l|}{226} & 10838,2083 & \multicolumn{2}{|c|}{47,956674} & \multicolumn{2}{|c|}{79,6146654} \\
\hline Column 2 & \multicolumn{2}{|l|}{226} & 4606,81 & \multicolumn{2}{|l|}{20,384115} & \multicolumn{2}{|c|}{171,478334} \\
\hline Column 3 & \multicolumn{2}{|l|}{226} & 4265,81 & \multicolumn{2}{|l|}{18,8752655} & \multicolumn{2}{|c|}{571,360239} \\
\hline Column 4 & \multicolumn{2}{|l|}{226} & 6377,53 & \multicolumn{2}{|l|}{28,2191593} & \multicolumn{2}{|c|}{691,353856} \\
\hline Column 5 & \multicolumn{2}{|l|}{226} & 8360,8 & \multicolumn{2}{|l|}{36,9946903} & \multicolumn{2}{|c|}{924,977483} \\
\hline Column 6 & \multicolumn{2}{|l|}{226} & 2704,3 & \multicolumn{2}{|l|}{11,9659292} & \multicolumn{2}{|c|}{264,913012} \\
\hline Column 7 & \multicolumn{2}{|l|}{226} & 2415,23 & \multicolumn{2}{|l|}{10,6868584} & \multicolumn{2}{|c|}{77,5322928} \\
\hline Column 8 & \multicolumn{2}{|l|}{226} & 17345,49 & \multicolumn{2}{|l|}{76,7499558} & \multicolumn{2}{|c|}{603,812406} \\
\hline Column 9 & 226 & & 21957,896 & 97,1588317 & & 183 & 96942 \\
\hline Column 10 & 226 & & 2607,656 & 11,5383009 & & 171 , & 20616 \\
\hline & & & Analysis of varian & & & & \\
\hline $\begin{array}{c}\text { Source of } \\
\text { variance } \\
\end{array}$ & SS & df & MS & F & & alue & F critical \\
\hline Between groups & 1798802,99 & 9 & 199866,999 & 534,438059 & 0 & & 1,88403338 \\
\hline Within groups & 841445,965 & 2250 & 373,975985 & & & & \\
\hline Total & 264024896 & 2259 & & & & & \\
\hline
\end{tabular}

The performed calculations indicate the essentially significant variation in the contextual data provided by the general educational institutions, which follows from the ratio $\mathrm{F}>\mathrm{F}_{\text {critical }}(534,438059>1,88403338)$ and low probability of acceptance of the null-hypothesis ( $\mathrm{P}$-value $=0$, which is lesser than 0.05$)$, i.e. the null-hypothesis $\left(\mathrm{H}_{0}\right)$ can be rejected and the alternative hypothesis $\left(\mathrm{H}_{1}\right)$ can be accepted.

In this connection, the fact, that the contextual data provided by the general education institutions vary significantly, can be considered proven. In this regard, the estimation of the effect of the impact of the contextual data provided by the general education institutions on the outcomes of the individual educational achievements of the fourth-grade pupils at the general education institutions of Voronezh region participating in the assessment of the metasubject results during the implementation of FSES for the primary general education.

To estimate this effect, let us use the correlation ratio $\eta^{2}$ (eta-square). $\eta^{2}$ (eta-square) is calculated as the ratio of between-group variance (SS between groups) to the total variance (SS total). By performing the corresponding division, we shall obtain the value for the strength of the factorial impact $-\eta^{2}=0.68130052(\sim 0.68$ or, expressed as a percentage, $68 \%$ ).
Thus, we can draw the conclusion that the outcomes of the individual educational achievements of the fourth-grade pupils at the general education institutions of Voronezh region in terms of assessing the metasubject results during the implementation of FSES for the primary general education are $68 \%$ dependent on all 9 parameters of the contextual data under study. The remaining $32 \%$ are determined by other variables (factors), the analysis of which is beyond the scope of the present study.

\section{CONCLUSION}

The results obtained in the course of the study serve as a theoretical-and-methodological basis for solving the relevant theoretical and practical problems concerning the use of methods for assessment and analysis of the outcomes of the individual educational achievements of the fourth-grade pupils in terms of assessing the metasubject results during the implementation of FSES for the primary general education. The results of the study expand the theoretical principles for establishment and use of new methodological practices for studying the impact of contextual data on the educational outcomes of the pupils at the general educational institutions. 


\section{REFERENCES}

[1] Using Contextual Data for Education Quality Assessment: The Experience of Tools Development and Testing/ G.A. Yastrebov, M.A. Pinskaya, S.G. Kosaretsky// Г.А. Ястребов, М.А. Пинская, С.Г. Косарецкий // Educational Studies. 2014. No. 4. Pages 58-95.

[2] Polivanova K.N. Educational Outcomes of Middle School in the Context of International Research // Psychological Science and Education. 2015. Volume 20. No. 4. Pages 19-30.

[3] Yeliseeva I.I., Yuzbashev M.M. General Theory of Statistics: Course Book / Edited by I.I. Yeliseeva, Edition 4, revised and enlarged edition. M.: Finance and Statistics ("Finansy I Statistika" Publishing House), 2002, 480 pages.

[4] Lyalin V.S. Statistics: Theory and Practice in Excel: Study Guide. M.: Finance and Statistics ("Finansy I Statistika" Publishing House); INFRA-M, 2010. 448 pages.

[5] Report on conducting the research work on "Monitoring of the individual educational outcomes of the fourth-grade pupils in terms of assessing the metasubject results during the implementation of FSES for the primary general education at the municipal general education institutions in Voronezh region (May 2018)" URL: http://образованиеврн.pф/wp-

content/uploads/electronic_systems/idevaluation/отчеты/ Отчет\%20Комплексная\%20работа\%204\%20класс\%20май\%20201 8.pdf (access date: November 21, 2018).

[6] Baraz V.R. Correlation and regression analysis of the connectedness of the commercial activity indicators using Excel software solution: Study Guide. Yekaterinburg: State Educational Institution of Higher Vocational Education "USTU-UPI," 2005, 102 pages. 